American Journal of Agricultural and Biological Sciences 5 (1): 84-88, 2010

ISSN 1557-4989

(C) 2010 Science Publications

\title{
The Pattern of Local Community-Based Management for Sustainable Rural Development in West Azarbaijan Province
}

\author{
${ }^{1}$ Loghman Rashidpour, ${ }^{1}$ Seyed Jamal Farajallah Hosseini, \\ ${ }^{2}$ Mohammad Chizari and ${ }^{1}$ Seyed Mahdi Mirdamadi \\ ${ }^{1}$ Science and Research Branch, Department of Agricultural Development, \\ Islamic Azad University, Tehran, Iran \\ ${ }^{2}$ Department of Agricultural Extension and Education, Tarbiat Modares University, Tehran, Iran
}

\begin{abstract}
Problem statement: Community-based management as incorporates both a top-down and bottom-up approach that involvement beneficiary sections such as local community, government states and non governmental organizations. It has also been applied to designate approaches where local communities play a central but not exclusive role in rural sustainable development process management. Approach: This study was survey method and is descriptive-correlation research, which was carried out to designee the pattern of community-based management and its application for sustainable rural development process in west Azarbaijan province. Study population were consisted 270 of, local community (rural councilors), offices experts in rural related office activities and agricultural and natural resources engineering organization NGO's members. Results: Results of structural equation modeling of the accepted characteristics indicated that latent variable such as "Stakeholder's Role" and "Affecting Factors" have positive effect and "Obstacles" latent variable has a negative role to design CBM. A structural equation indicated these variables altogether account $93 \%$ of variance $\left(\mathrm{R}^{2}=0.93\right)$ in designing community-based management. Conclusion/Recommendations: On the basis of structural model, we can conclude that factors, stakholers and obstacles have important affect on community-based management. Overall community based management will have more impotent role in rural developments process planning, organizing, staffing, controlling and directing.
\end{abstract}

Key words: Community-based management, sustainable rural development, structural equitation modeling

\section{INTRODUCTION}

Collaborative or cooperative management has been defined in many ways but is generally thought of as a power-sharing arrangement between the government and local stakeholder groups. Singleton (1998) defines co-management as 'the term given to governance systems that combine state control with local, decentralized decision making and accountability and which, ideally, combine the strengths and mitigate the weaknesses of each'.

Closely related to "co-management as network" is the concept of community-based management (WelchDevine, 2008). Community-based approaches can form part of the co-management process and when community-based management is a large component of a co-management process, the result can be thought of as "community-centered co-management" (Pomeroy, 2001; Pomeroy and Rivera-Guieb, 2006). Such an approach would be toward the maximum end of Tyler

Corresponding Author: Loghman Rashidpour, Science and Research Branch, Department of Agricultural Development, Islamic Azad University, Tehran, Iran
(2006) community power continuum that called community control.

This research relies on a broad definition of Community-based management as incorporates both a top-down and bottom-up approach. This collaborative process is based on the participation of all individuals and groups that have a stake in the management framework. Social, cultural and economic objectives are an integral part of the management framework. Government retains responsibility for overall policy and coordination, while the local community plays a large role in management. Also Community-based management creates the opportunity to take advantage of scientific, technical knowledge and related NGOs and local or traditional knowledge (Rashidpour and Hosseini, 2007). This definition leaves sufficient flexibility for the definition of the system but highlights interest in the interactions between state and non-state actors emphasizes on multi-sectoral collaboration in order to minimize fragmentation of efforts, waste of 
resources and competition for participatory actions. This is specifically an attempt to find new solutions for the failure of top-down approaches to resource conservation and sustainability. Community-Based Management (CBM) has been seen as a conservation, empowering, poverty reducing and/or general rural development strategy (Rural Livelihood Evaluation Partnership, 2004; Masduqi et al., 2007). Such community-based approaches create opportunities to strengthen social capital and community relations and to develop effective institutions for the management of sustainable rural development (Rural Livelihood Evaluation Partnership, 2004). Sometimes, it has also been applied to designate approaches where local communities play a central but not exclusive role in natural resource management (Rotha et al., 2005).

Danida (2007) and Sarrafi (2003), called this approach as "Good governance" system as a development strategy at local level. Therefore, the establishment and maintenance of good governance or "appropriate decision-making arrangements" is the only feasible way to prevent the failure (or ensure the success) of rural sustainable development.

Despite gains realized, community-based natural resource management as a Construct is not easy and takes time and resources. Reluctance to change is perhaps one of the greatest challenges to CBM (Meshack et al., 1998). In other writings, Danida (2007) has explained one of the tricky issues in approaching the national level is that, for a number of reasons, central governments and line ministries may be hesitant to delegate power to local organizations. Thi Kim and Van Luong (2008) pointed out that a, major challenges include complexity of the method, high costs (time and resources) and lack of skilled community facilitators.

The main goal was to design the pattern of local community-based management for sustainable rural development in the West Azarbaijan Province. The objectives of this study are as follows: (1) What stakeholders can be formed the structure and framework of a community-based management? And what is their role and responsibilities? (2) What are efficient factors for design the pattern of communitybased management? (3) What are obstacles for design the pattern of community-based management? (4) What community-based management will do for sustainable rural development in west Azarbaijan Province?

\section{MATERIALS AND METHODS}

The methodology used in this study involved a combination of descriptive and quantitative research and included the use of correlation, regression and descriptive analysis as data processing methods. A
Delphi survey methodology was used to develop the theoretical framework of the study. The statistical population consisted of local community (rural council members), senior experts in related fields from departments of agriculture and natural resources, environment and state officials and members of Agricultural and Natural Resources Engineering Organization who were involved in activities related to community-based management. Sample size included 120 rural council members, 60 senior experts from Ministry of Agriculture and 90 Agriculture and Natural Resources Engineering Organization members. In this study attitudes towards community-based management approach were measured by set of questions about: "role of community in community-based management", "role of public sector in management based on community", role of non-governmental sector in the community-based management", affective and appropriate factors", obstacles on the formation of community-based management approach" and, "role of community-based management in sustainable rural development process". The content validity of questionnaire were measured by a group of extension, rural and agricultural development specialists. A pilot test was conducted to determine the questionnaire's reliability and the Cronbach's alpha was 0.78. Data collected was analyzed using the Statistical Package for the Social Sciences (SPSS) and Linear Structural Relationships (LESREL).

\section{RESULTS}

The results of this study showed that $44.5 \%$ of respondents were member of local communities, $22.2 \%$ were employed in public sector and $33.3 \%$ were NGOs members. The average age of local community members were 41 years with average of 6 years of membership in rural council. The average age of public sector employees was 36 years old, with average of more than 10 years of experiences. The average age of non governmental organization members was 33 years old with average experience of 6.5 years.

The respondent from local community, public sector and NGOs were asked to indicate their perception about factors and challenges that affect the community-based management.

The Structural Equation Model (SEM) was used to examine a series of relationships among variables simultaneously without being influenced by measurement. Based on the correlation coefficients, three structural models were established:

- X-model indicated that "Community Role" had the highest impact factor loadings of 0.85. It appears to be the best indicators of "Stakeholders". The latent 
variable "Stakeholders" explains about $72 \%$ of variance in "Community Role" (Table 1). "Educational Factor" has largest factor loading of 0.90 ; it appears to be the best indicators of "Factors" and it explains about $81 \%$ of variance in affecting factors

"External Obstacle" has a large factor loading of 0.86 ; it appears to be the best indicators of limitation. This variable explains about $73 \%$ of variance of "External Obstacle". The inter correlations have already been described in Table 1 and Fig. 1 for the measured variables

- Y-Model indicated that "Organizing" and "Controlling" have largest factor loadings of 0.79 ; It appear to be the best indicators of CBM. The inter correlations which have already been described in Table 2 and Fig. 1, showing that the other indicators had a large factor loading and were important. Completely Standardized Solutions of the structural model (model 3) showed that observed latent variables in this study; "Factors", "Beneficiaries" and "Obstacles" have factor loadings of $0.66,0.50$ and-0.17 respectively. It appears the latent observed variables "Factors" and "Beneficiary Role" has positive affect and Limitation has a negative affect on Community-Based Management (CBM). These latent observed variables explain about $93 \%$ of variance in community based management (Table 3 and Fig. 1)

Eventually, based on the all of above results, CBM was affected by Stakeholders, Factors and Obstacles (Model 1). This model shows the estimation of regression weight, Such as an explained above on X, Y and structural models. The results of the complete Structural Equation Model (SEM) for observed and latent variables are provided in Fig. 1. The results of fit indices used to evaluate the adequacy of this model showed that a $\mathrm{X}^{2}$ of 124.93 , the significant level was 0.002, which means that based Chi-Square statistic rejects this model (Kalantari, 2009), but Chi-Square value is the traditional measure for evaluating overall model fit. And there are also a number of severe limitations in its use. Firstly, this test assumes multivariate normality and severe deviations from normality that may result in model rejections even when the model is properly specified (McIntosh, 2006).

Table 1: Estimation of regression weight, $\mathrm{t}$-value and $\mathrm{R}^{2}$ of $\mathrm{X}$-model

\begin{tabular}{llll}
\multicolumn{1}{c}{ variables } & & & \\
\hline Observed X & $\mathrm{SC}^{1}$ & $\mathrm{~T}$ & $\mathrm{R}^{2}$ \\
\hline Community role & 0.85 & $\mathrm{RV}^{2}$ & 0.72 \\
Government role & 0.69 & 12.53 & 0.47 \\
Non-government role & 0.69 & 12.46 & 0.46 \\
Management factors & 0.76 & $\mathrm{RV}$ & 0.57 \\
Social factors & 0.88 & 15.56 & 0.78 \\
Political factors & 0.74 & 12.71 & 0.55 \\
Economic factors & 0.70 & 11.81 & 0.48 \\
Educational factors & 0.90 & 16.03 & 0.81 \\
External limitations & 0.86 & $\mathrm{RV}$ & 0.73 \\
Internal limitations & 0.72 & 14.30 & 0.51 \\
\hline 1: Completely stancar
\end{tabular}

1: Completely standardized solution; 2 : Reference variable

Table 2: Estimation of regression weight, $\mathrm{t}$-value and $\mathrm{R}^{2}$ of $\mathrm{Y}$-model variables

\begin{tabular}{llll}
\hline Observed-Y & $\mathrm{SC}$ & $\mathrm{T}$ & $\mathrm{R}^{2}$ \\
\hline Planning & 0.78 & $\mathrm{RV}$ & 0.61 \\
Organizing & 0.79 & 14 & 0.62 \\
Staffing & 0.76 & 13.51 & 0.58 \\
Controlling & 0.79 & 14.17 & 0.63 \\
Directing & 0.67 & 11.46 & 0.44 \\
\hline
\end{tabular}

Table 3: Regression relationship of latent variables

\begin{tabular}{llll} 
& Latent X & & \\
& - & & \\
Latent Y & Beneficiaries role & Affecting factors & Obstacles \\
\hline CBM & 0.50 & 0.66 & -0.17 \\
\hline
\end{tabular}

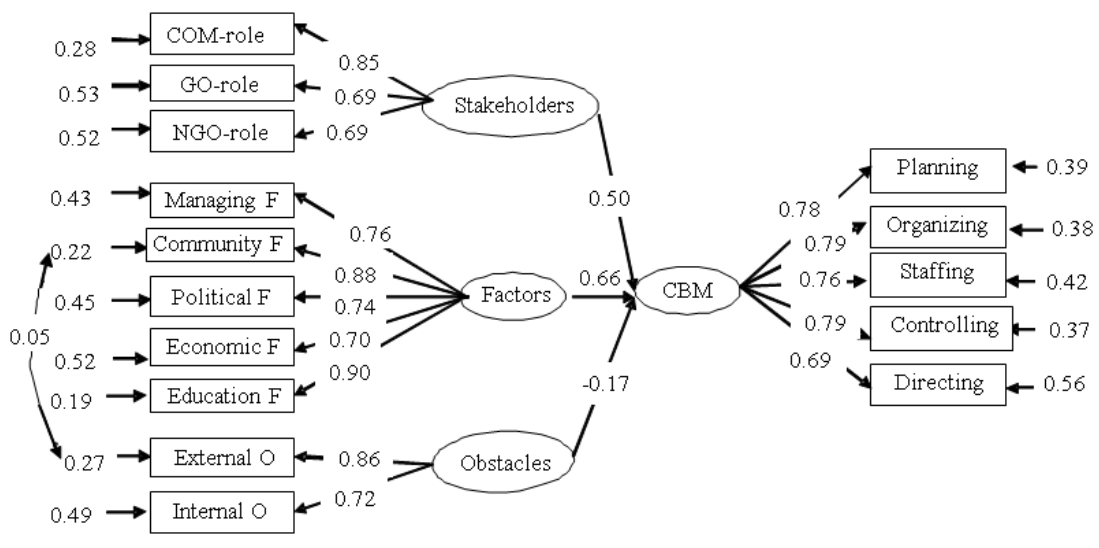

Fig. 1: Estimation of regression weight (standardized factor loadings) of variables inter relations 
Secondly, because the Chi-Square statistic is in essence a statistical significance test. It is sensitive to sample size which means the Chi-Square statistic nearly always rejects the model when large samples are used (Bentler and Bonnet, 1980). Due to the restrictiveness of ChiSquare, researchers have sought alternative indices to assess model fit (Hooper et al., 2008). Therefore, measures of fit were examined including the Goodness of Fit Index (GFI = 0.94), the Comparative Fit Index $(\mathrm{CFI}=1.00)$ and Root Mean Square Error of Approximation (RMSEA $=0.046$ ). This model appeared to fit well enough, with the GFI and CFI both greater than 0.90 and RMSEA less than 0.05. Based on the above fit indices, it can be concluded that the final model fits the proposed model.

\section{DISCUSSION}

Based on the X-model, we can conclude that: (1) "Community Role" is superior to the two other sectors considered (GO, Role and NGO, Role) in predicting the "Stakeholders" role in CBM. In effect, this scale is best adjusted to the data and has the strongest predictive power. (2) "Educational Factor" is superior to the four other factors considered (management, social, political and economic factors) in predicting the affecting factors in CBM and has the strongest predictive power. (3) "External Obstacle" is superior to the other obstacles considered (internal obstacle) in predicting the restriction in $\mathrm{CBM}$ and has the stronger predictive power.

Based on the Y-model, "Community-Based Management" explains about 61,62,58,63 and 44\% of variance in "planning", "Organizing", "Staffing", "Controlling" and "Directing" affects in rural sustainable development process.

On the basis of structural model, we can conclude that factors, stakholers and obstacles have important affect on community-based management.

Moreover, the structural equation modeling had an acceptable goodness of fit with the proposed model. This result confirms the previous research (Carlsson and Berkes, 2005; Plummer and Armitage, 2007; Borrini-Feyerabend et al., 2001; Faryadi, 2005; Meshack et al., 1998; Olyel, 2006; Welch-Devine, 2008).

\section{CONCLUSION}

Overall, this research provides an initial exploration of new management practices such a community-based management approach that involves many stakeholders and should be adopted for success and sustainability in rural strategy development. This approach is indicated by three indicators, e.g., stakeholders, factors and obstacles. The most representative indicator for stakeholders' role in community-based management is local community role. So, it is important to considered rural people and community in rural development managing process, also the most representative indicator for effective factors is educational and social factors that confirmed the importance of local community role in this approach. The community-based management for sustainable rural development can perform significantly the planning, organizing, staffing, controlling and directing of rural sustainable development process. On the basis of the results of the research, it is recommended that strategy of rural sustainable development should consider local community such as main partnership and stakeholder.

\section{REFERENCES}

Bentler, P.M. and D.C. Bonnet, 1980. Significance tests and goodness of fit in the analysis of covariance structures. Psychol. Bull., 88: 588-606.

Borrini-Feyerabend, G., M.T. Farvar, J.C. Nguinguiri and V.A. Ndangang, 2001. Co-Management of Natural Resources: Organizing, Negotiating and Learning-by-Doing. GTZ and IUCN, Kasparek Verlag, Heidelberg (Germany), pp: 108.

Carlsson, L. and F. Berkes, 2005. Co-management: Concepts and methodological implications. J. Environ. Manage., 75: 65-76.

Danida, 2007. Community-based natural resource management. Technical Advisory services, Ministry of Foreign Affairs of Denmark. http://www.ifad.org/pub/other/cbnrm.pdf

Faryadi, Sh., 2005. A Methodology for Participatory local Environmental planning. J. Environ. Stud., 31: 14-29.

Hooper, D., J. Coughlan and M.R. Mullen, 2008. Structural equation modeling: Guidelines for determining model fit. Elect. J. Bus. Res. Methods, 6: 53-60.

Kalantari, K., 2009. Structural Equitation Modeling in Socio-Economic Research. 1st Edn., Farhange Saba Press, Tehran, Iran, ISBN: 987-964-2935-499, pp: 243.

McIntosh, C., 2006. Rethinking fit assessment in structural equation modeling: A commentary and elaboration on Barrett (2007). Person. Individ. Diff., 42: 859-867.

Masduqi, A.N., E.S. Endah and W. Hadi, 2007. Achievement of rural water supply services according to the millennium development goalsCase Study in the Brantas River Basin. J. Purifikasi, 8: 115-120. 
Meshack, M., O. Jeff and O. Thomas, 1998. Challenges and opportunities in community-based dry land natural recourses management. A community member expressing her view on management of the community based organization. Regional Programme on Sustainable Use of Dry land Biodiversity (RPSUD) National Museums of Kenya.

http://www.uneca.org/aec/documents/Meshack\%20 Malo_Jeff\%20Odera\%20_Thomas\%20Ochuodho.p df

Olyel, A.D., 2006. Right tool, Wrong target? Comanagement in the Ugandan fishery sector. A thesis submitted in partial fulfillment of the Masters Degree in International Fisheries Management, Norwegian College of Fisheries Science University of Tromson, pp: 124.

Plummer, R. and D.R. Armitage, 2007. Charting the new territory of adaptive co-management: A Delphi study. Ecol. Soc., 12: 10.

http://www.ecologyandsociety.org/vol12/iss2/art10/

Pomeroy, R., 2001. Devolution and Fisheries CoManagement. In: Collective Action, Property Rights and Devolution of Natural Resource Management: Exchange of Knowledge and Implications for Policy, Meinzen-Dick, R.., A. Knox, and M. Di Gregorio (Eds.). German Foundation for International Development/Center for Agricultural and Channel, (DSE/ZEL), Feldafing, Germany.

Pomeroy, R.S. and R. Rivera-Guieb, 2006. Fishery CoManagement: A Practical Hand Book. 1st Edn., CABI Publishing, Cambridge, USA., pp: 240.

Rashidpour, L. and S.J.F. Hosseini, 2007. Communitybased management approach in natural recourse protection. J. Agric. Extens. Rural Dev., 187-204. (In Persian).
Rotha, K.S., 2005. Understanding key CBNRM concepts, The Development of Community Based Natural Resource Management (CBNRM) in Cambodia.

Rural Livelihood Evaluation Partnership (RLEP), 2004. Community based (natural resources) management. UK Department for International Development for the Benefit of 'Developing Thematic Lessons Paper Series-3, Dhaka, Bangladesh.

Sarrafi, M., 2003. Good governance: Instrument field of rural community development in Iran, Studies based on Hamadan province. Proceeding of the Rural Development Congress, July 10-10, Institute of Rural Development, pp: 100-102. (In Persian).

Singleton, S., 1998. Constructing Cooperation: The Evolution of Institutions of Co-Management. University of Michigan Press, ISBN: 047210957X, pp: 165.

Thi Kim, N.Y. and P. Van Luong, 2008. Participatory Village and Commune Development Planning (VDP/CDP) and its contribution to local community development in Vietnam. Community Dev. J., 43: 329-340.

Tyler, S.R., 2006. Communities, Livelihoods and natural resources: Action research and policy change in Asia. International Development Research Centre, (IDRC), Canada, pp: 420.

Welch-Devine, M., 2008. From common property to co-management: Implementing natural 2000 IN SOULE. A thesis submitted in partial fulfillment of the Degree Doctor of Philosophy, University of Georgia, ATHENS, pp: 145-154. 